\title{
Quali-Quantitative Analysis of Brazilian Environmental Licensing of Hydropower Plants
}

\author{
Fabio Giusti Azevedo de Britto1,2, José Paulo Soares de Azevedo1, \\ Cynara Alets Sthuasth Souza de Melo França' ${ }^{1}$, Rodrigo Cunha Wanick ${ }^{1}$, \\ Leandro Andrei Beser de Deus ${ }^{1,3 *}$, Marcos Aurélio Vasconcelos de Freitas ${ }^{1}$ \\ ${ }^{1}$ Federal University of Rio de Janeiro, Rio de Janeiro, Brazi \\ ${ }^{2}$ National School of Statistical Sciences, Rio de Janeiro, Brazi \\ ${ }^{3}$ State University of Rio de Janeiro, Rio de Janeiro, Brazi \\ Email: ${ }^{*}$ leandroandrei@yahoo.com.br
}

Received 24 May 2015; accepted 19 July 2015; published 24 July 2015

Copyright (C) 2015 by authors and Scientific Research Publishing Inc.

This work is licensed under the Creative Commons Attribution International License (CC BY). http://creativecommons.org/licenses/by/4.0/

(c) () Open Access

\section{Abstract}

The use of the extraordinary hydroelectric potential of the Amazon Basin originated an increase in the offer of renewable energy in Brazil, which, in its turn, leads to conflicts and a lack of consensus among different players owing to the potential negative impacts related to the construction and operation of large hydroelectric power plants in relatively well preserved areas. In this context, environmental licensing is one of the national environmental policy's main instruments for making decisions regarding the use of the hydroelectric potential, especially the rivers of the Amazon Basin. Nevertheless, this significant instrument has its limitations and requires adjustments in order to better aid the decision making process regarding the use of water resources and land with the goal of increasing the offer of electric energy.

\section{Keywords}

Expansion of Renewable Energy, Environmental Licensing, Hydropower Plants, Energy

\section{Introduction}

This article aims to point out the main issues and limitations in harmonizing the increase of renewable energy sources in Brazil through the use of the hydroelectric potential of the country with the legal mechanisms created

\footnotetext{
${ }^{*}$ Corresponding author.
}

How to cite this paper: de Britto, F.G.A., de Azevedo, J.P.S., de Melo França, C.A.S.S., Wanick, R.C., de Deus, L.A.B. and de Freitas, M.A.V. (2015) Quali-Quantitative Analysis of Brazilian Environmental Licensing of Hydropower Plants. International Journal of Geosciences, 6, 692-704. http://dx.doi.org/10.4236/ijg.2015.67056 
to reduce and compensate negative environmental impacts. In this article, the focus is on the environmental licensing of hydropower plants, which is the main instrument of the Brazilian legislation in the decision making process for the environmental area.

The analyses and statements made in this article aim to contribute to the efficiency of the environmental licensing process in Brazil, with speedier decisions, less political influence, more technical assessments and a greater capacity for reducing socio-environmental impacts created by the construction and operation of large hydroelectric dams.

Brazil stands on a privileged position and may possibly become a model in energetic expansion thanks to its impressive hydroelectric potential—about 260.000 MW [1]. However, for that to happen, the government needs to adapt to the challenges brought by higher energy demand and consequent environmental restrictions to hydroelectric use (legislation, land use zoning and environmental licensing).

This issue can be better understood by analyzing three factors of the contemporary historical context. First, there is a global consensus regarding the importance of choosing renewable and clean energy sources, which is demonstrated by the creation of policies by countries and international entities such as the European Union [2]-[4].

Second, the demand for energy is increasing due to the population growth and the increase of the power consumption of developing countries or countries that are facing a strong economical growth, which is the case of Brazil. In consequence, the Brazilian government has created policies that focus on increasing the energy supply for industries and especially for low income citizens [5].

Third, $40 \%$ of the Brazilian hydroelectric potential is located on the Amazon Basin, an area that has one of the largest biodiversities on the planet and possibly the largest amount of living biomass in a single country. In addition, it is also where important territories of the remaining indigenous population of the country are located, which is cause for strong socio-environmental restrictions to the use of the hydroelectric potential of the area. According to estimates of the National Energy Plan for 2030, made by the Ministry of Mines and Energy, approximately $62 \%$ of the hydroelectric potential of the Amazon has some sort of restriction imposed by socioenvironmental zoning (Permanent Preservation Areas, Conservation Units, Indian Reservations, Quilombola ${ }^{1}$ Reservations and other categories) [6].

In this context, environmental licensing is an instrument of the National Environmental Policy, which was instituted by Law 6.938 in 1981. Its main objective is to help the decision making process regarding the best alternatives for using natural resources by determining which factors may mitigate or compensate the negative impacts caused by each project [7]. The main instrument of the environmental licensing process is the Environmental Impact Study (EIA). For a licensing system to be effective, it must minimize the probability of a project with large environmental impacts being implemented [8]. Regarding this subject, several authors have analyzed the capacity that studies and methods of evaluating environmental impacts have in promoting sustainable development and in minimizing the negative impacts of projects and sectoral planning [9]-[14].

To the contrary, however, there are project managers and specialists who say that environmental licensing in Brazil, especially in the Amazon region, is a factor that limits the development of the hydroelectric sector in the Amazon.

The long period it takes for the environmental licenses to be issued and the sectoral conflicts that commonly end up becoming legal disputes are both obstacles for several projects which were previously classified as technically feasible.

As the World Bank Report states, "the combination of regulatory uncertainties created by the environmental legal milestone and, to a lesser degree, by the energetic legal milestone, are a risk to potential investors". These investors, consequently, start pricing the aforementioned risk and establish a higher cost to consumers [15].

\subsection{Summary of Hydroelectric Use in the World}

The percentage of electric energy of hydraulic origin produced in the world is still relatively low, in 2010, it was calculated to be about $16 \%$ [16]. However, there are countries with geomorphologic and hydrologic characteris-

\footnotetext{
${ }^{1}$ While slavery existed in Brazil (from the $16^{\text {th }}$ to the $19^{\text {th }}$ centuries), slaves who escaped used to hide in secluded and protected constructions in the midst of the forest. These constructions were known as quilombos. Quilombola territories or lands are areas occupied by quilombos which remain untouched since the colonial period. They can be recognized as such by Brazilian law once their inhabitants declare an area to be a Quilombola territory.
} 
tics that, in association with technical and financial resources, can guarantee a high level of use of the hydraulic potential on the energy matrix for producing electric energy. Such is the case of Norway, Brazil and Venezuela, all three of them presenting a percentage of electric energy of hydraulic origin higher than $60 \%$. For Norway, it was $94.7 \%$ and for Brazil it was $78.2 \%$ of the total energy produced in 2010.

In absolute terms, considering the total energy produced and the capacity utilization, Brazil is the second largest producer of electrical energy of hydraulic origin, the first being China. In 2010, these two countries produced respectively 722 and 403 TWh of hydroelectric energy, followed by Canada with 352 TWh and by the United States with 286 TWh. Together, these four countries produced 50\% of the hydroelectric energy, representing $44 \%$ of the world's capacity utilization in 2010 .

\subsection{Brazil's Hydroelectric Potential}

For characterization purposes of the hydroelectric potential, it will be considered the territory of the Hydrographic Basin since hydroelectric potentials are mostly defined by the hydrologic characteristics of a region.

On the topic of the hydroelectric potential to be explored in the country, the data collected by the Brazilian Hydroelectric Potential Information System-SIPOT [1] estimates that about $40 \%$ of the total potential is located on the Amazon Basin, which goes beyond Brazilian territorial limits to include part of other South American countries, as shown in Figure 1.

Excluding the remaining potential of the Amazon Basin (16.000 MW), i.e., considering theoretical calculations without identifying the possible dam, even imprecisely, the potential of the basin is calculated to be 77.058 MW. It is distributed among thirteen sub-basins, four of which (Tapajós, Xingu, Madeira e Trombetas) are responsible for almost 90\% of its total, as shown in Figure 2.

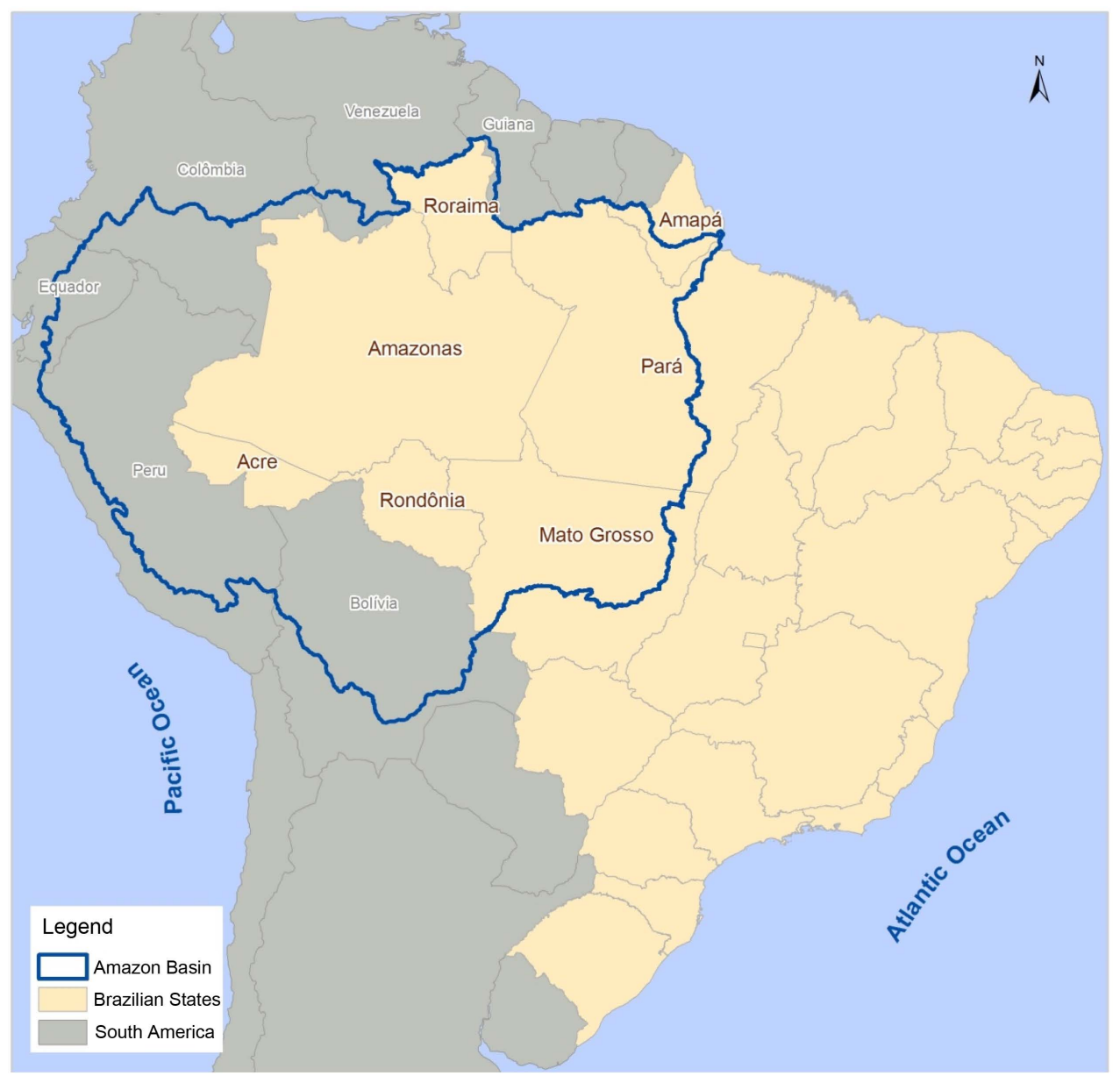

Figure 1. Location of the Amazon basin. 


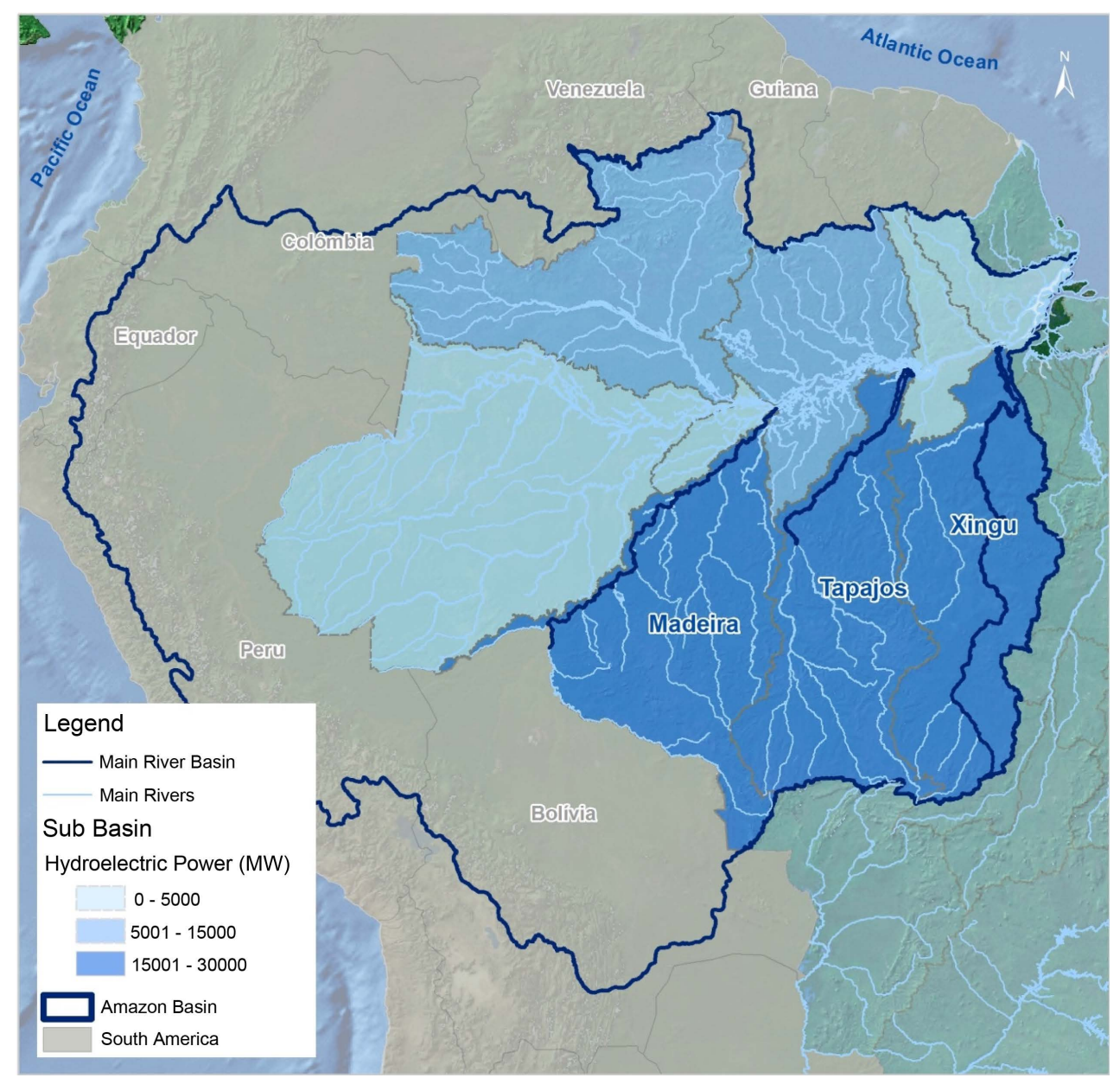

Figure 2. Hydroelectric potential per sub-basin of the Amazon basin.

Nevertheless, it should be emphasized that there is a difference between the available estimated potential and the usable estimated potential, for the use and occupation of the Amazon Basin's territory is limited by several restrictions that prohibit the exploration of natural resources, including the hydraulic force for energy generation. Therefore, only $38 \%$ of the hydroelectric potential of the Basin is legally available for exploration.

Even the hydroelectric potential that does not have any legal restrictions is subject to socio-environmental conditions imposed by legislation and agencies involved in the process of environmental authorization and licensing. Thus, it is important to know the institutional and legal system that controls the licensing process in order to understand how these aspects may influence the decision making process concerning the expansion of the energy offer in Brazil.

\section{Brazilian Legal Framework}

Brazil is a Federative Republic with a superior paramount law, the 1988 Federal Constitution, which establishes a political and administrative organization divided into: the Union, represented by the Federal Government; the States, represented by state governments; the Federal District, center of federal political power and administrative capital of the country; and the cities, represented by city (local) administrations.

In the beginning of the 1980s, the National Environment System (Law 6.938) was created, involving agencies and entities from the Union, states and municipalities. It would become the foundation for the guidelines of the National Environmental Policy.

Presently, the most important body in the environmental licensing process in the federal context is the Brazilian Institute of Environment and Renewable Sources (IBAMA), created on 1989 and later linked to the Ministry 
of Environment (1992). Its main responsibilities are controlling the environmental policy, monitoring, environmental control and carrying out the national environmental policies on the federal level, as well as environmental licensing, quality control and inspection.

\subsection{Federal Environmental Licensing Procedures in Brazil}

The process to obtain a federal license in Brazil is divided in three phases. At the end of each phase, an authorization is obtained through a federal license issued by IBAMA and in all of them it may be necessary to obtain licenses and complementary authorizations from other bodies on the state or municipal level. The three phases of the federal licensing are:

1) Previous License (LP) - Issued on the preliminary phase of the planning of the project or activity, approving its location and conception and certifying its environmental viability. It also establishes the basic requirements and conditions that should be observed on the next stages of its implementation;

2) Installation License (LI) - It authorizes the installation of the project or activity according to the specifications previously determined. In this phase, the environmental control measures are determined, as well as other conditions for the engineering work;

3) Operating License (LO) - It authorizes the operation of the activity or project after the conditions determined on the first two licenses are verified. In this stage, the environmental control measures are determined, as well as the conditions under which the project will operate.

\subsubsection{Obtaining the Previous License (LP)}

For a Previous License to be obtained, IBAMA opens a process and creates a Term of Reference (TR), which will determine the guidelines and the basic requirements for elaborating the Environmental Impact Study (EIA) and its respective Environmental Impact Report (RIMA) that should be made by the project manager.

Both EIA and RIMA have the objective of providing the most information they can about the project's positive and negative impacts.

After the Study is approved, the licensing body may find it necessary to hold a Public Hearing. When the Study is approved and/or after the complementary solicitations are met, the project manager pays the licensing fees and then finally obtains the Previous License.

Similarly to the other licenses, the issuance of the Previous License is subject to several conditions that determine which actions and procedures should be made in order to mitigate and compensate the negative socioenvironmental impacts.

\subsubsection{Obtaining the Installation License}

In this stage, a Basic Environmental Plan (PBA) and an Environmental Compensation Plan (PCA) should be elaborated. The first document will specify which the control and mitigation measures are, as well as how they should be developed through the Environmental Programs proposed on the EIA. On the PBA, all actions and programs developed over the stages of the project should be mentioned, from the beginning of the construction work to the monitoring that occurs while it is in operation. The actions that will be taken to comply with the conditions from the Previous License should also be determined. In its turn, the PCA determines which measures should be taken to compensate the negative impacts of the project.

Additional complementary plans can be requested before the LI is issued. If the installation of the project requires deforestation or inundating vegetation, a Forest Inventory is required to validate the issuing of the Vegetation Suppression Authorization. In case there is a risk of eroding/degrading the land, a Plan to Recover Degraded Areas (PRAD) is necessary while the enterprise is being installed or while it's operating. Most commonly, this is a requirement for mining enterprises and hydroelectric dams. Once the Basic Plan is approved and the complementary requirements are met, the project manager pays the fees and the Installation License is issued.

\subsubsection{Obtaining the Operating License}

The phase of obtaining the Operating License begins with IBAMA analyzing the reports that contain the results of the Environmental Programs proposed on the Basic Environmental Plan. The results presented should prove that all the conditions required by the LP and LI are being met; in case one of previous requirements are not obeyed, the Operating License may be denied. However, it is very common to demand a complementary action or 
to transfer the condition of a license to the list of requirements of the next license, which in this case is the LO.

After IBAMA approves it and the possible complementary measures are taken, the project manager pays the fees and the Operating License is issued.

It is worth mentioning that, at any moment, in any of the three licensing phases (LP, LI and LO), the Public Ministry (Federal or State) can intervene if provoked by civil society or anybody involved in the process and also if any law is broken. The Ministry can demand explanations, add complementary measures to the environmental requirements and mediate lawsuits that involve the project.

For hydropower plants, it is on the third phase that the licensing process is different. In addition to the final reports of the Environmental Program and the Vegetation Suppression Program that are needed in every environmental licensing, IBAMA requires the presentation of a Plan for Usage of the Reservoir's Vicinity (PACUERA), which analyzes the environment based on the use and occupation of land, as well as the economic situation of the communities that are located on the area that will be inundated.

In addition to the procedures that are part of all environmental licensing, the construction of a hydroelectric installation includes complementary phases to obtain permission to use the water. Regulatory agencies ANA and ANEEL are involved in this final part of the process.

\section{Methodology}

To obtain a qualitative analysis of the subject, international references on the topic of licensing and environmental impact were studied. However, international articles on this subject tend to focus more on the analysis of the methods and on the effectiveness of the environmental impact studies; it is not common for them to analyze the licensing process in its entirety. This fact can be explained mainly by the differences in each country's legislation and bureaucratic procedures. In most cases, the only aspect that all countries have in common is the need to create an impact study. Licensing systems of countries such as Canada, United States, Colombia and China were analyzed. Nevertheless, the similarities were rare when these countries were being compared with each other and they were even rarer when international models were compared with the Brazilian model. The few common aspects found were of minor relevance.

Considering that each country's environmental process is very specific, the analysis was based on Brazilian studies and articles. Three studies which analyze the efficiency and the challenges of Brazil's environmental licensing, focusing on hydroelectric installations, were used for reference: the "Operational Nature Auditing Report on Federal Environmental Licensing," made by the Court of Accounts of the Union (TCU) ${ }^{2}$ in 2008; the World Bank Report "Environmental Licensing of Hydroelectric Installations in Brazil," published in March 2008, and the study made by the Center of Research and Studies of the Senate, "Environment and Energy: Beliefs and Science in Environmental Licensing: Issues that Hamper Environmental Licensing in Brazil,” from June 2011.

For the quantitative analysis, the data considered were available on the Generation Information Bank of the National Electric Energy Agency-BIG/ANEEL and on the Computerized System of the Federal Environmental Licensing of IBAMA-SILAMF/IBAMA.

The environmental licensing of hydropower plants (UHEs) can have different aspects depending on the river's domain and on the beginning date of the licensing process or power plant operation.

Hydropower plants, that started operating prior to 1986, the year the environmental licensing legislation was created, are exempt from this process. In these cases, when the environmental agency finds it necessary, an environmental regularization process is requested. For the Operating License to be issued, some requirements must be fulfilled, such as the elaboration of a Basic Environmental Plan and monitoring studies, the creation of Environmental Programs and the mitigation of impacts.

For projects on federal rivers or projects affecting more than one federation state, the licensing is processed on the federal level, under the responsibility of IBAMA. For projects involving state or municipal rivers, therefore affecting the area more locally, licensing is done by the environmental state agencies (OEMA).

Of the 204 hydropower plants registered in BIG/ANEEL, only 49 of them are also in SILAMF (Computerized System of Federal Environmental Licensing), which is controlled by IBAMA. In SILAMF, the power plants can

${ }^{2}$ The Court of Accounts of the Union (Tribunal de Contas da União-TCU) is the external auditing body of the Federal Government. One of its main attributions is to analyze the accounts presented by the Government, the associated agencies and the public bodies. Moreover, it has the prerrogative of making operational inspections and technical audits focused on the legality, legitimacy and economic transparency of an activity. 
be categorized according to the phase of the environmental licensing in which they belong.

For the quantitative analysis of the licensing process of hydropower plants on a federal level, the following requirements were considered:

- The project should be registered in IBAMA's Computerized System of Federal Environmental Licensing;

- The project should have received at least the Previous License;

- The data related to licenses that were going through Environmental Regularization were not considered, as well as the licenses that did not have enough data on the System.

- When counting the conditions of each license (LP, LI, LO), the General Conditions were not taken into account, but rather the specific conditions, for only they have technical and financial consequences.

- When counting the specific conditions, each sub-item, even if it was not numbered, was taken into account. For instance, on cases in which the condition was the execution of Environmental Programs, each Program was counted as a single specific condition.

- The date considered as the beginning of the process is the date stated on SILAMF;

- The analysis considered three different groups:

- Projects that are already operating, which have the three licenses (LP, LI, LO)

- Projects that are being implemented, which received only the LP and LI.

- Projects that have received only the LP.

- The following data were analyzed:

- Elapsed time between the beginning of the process on the environmental agency and the issuing of the first license;

- Elapsed time between the arrival of the Environmental Impact Study on the environmental agency and the issuing of the first license;

- Number of conditions specific to each license.

To make a quantitative analysis of the discrete variables, the In Stat 3 software was used to calculate the mean value, the medians, the standard deviation, the standard error and the sample normality test. The sample distribution was also analyzed through dispersion diagrams. They were created using Microsoft Excel 2010 and In Stat 3.

\section{Discussion}

\subsection{Quantitative Analysis of the Environmental Licensing Process for Hydroelectric Projects}

\subsubsection{Time for Issuing the Previous License}

By adding all limit deadlines determined by federal legislation (for procedures, analyses and answer of the environmental agency and intervening agencies), it would take 9.3 months to obtain a Previous License. Nevertheless, this time frame does not include the time the project manager needs to elaborate the Environmental Impact Study, to make adjustments and to take complementary actions requested by the agencies.

The analysis of the 21 processes available on SILAMF that began between 1994 and 2008 indicates that it is not possible to predict how long it will take for a license to be issued, especially the Previous License. The data analyzed present an average of 42.8 months between the opening of the process on the environmental agency (IBAMA) and the issuing of the first environmental license, and an average of 19.3 months between the presentation of the Environmental Impact Study and the issuing of the LP. However, the statistical analysis of these data had a very high standard deviation -25.9 and 12.8 respectively for the two situations analyzed.

The distribution analysis of the elapsed time between the beginning of the process and the issuance of the LP indicated that in $80.9 \%$ of the cases it took 10 months at least and 55 months at the most. When the registration date of the EIA on the environmental agency was taken as reference, the conclusion was that in $71.4 \%$ of the analyzed processes the elapsed time for the LP to be issued was between 5 and 30 months.

As for the elapsed time between the approval of the Previous License and the approval of the Installation License, 18 processes registered at SIMLAF were analyzed and the average was 17.2 months. However, the standard deviation was 8.08. Although it is lower than the standard deviation found for the issuance of the LP, this value is still considered high to define a measure of dispersion, which indicates that there is a considerable fluctuation of the variables around the average.

The analysis of the distribution of the elapsed time between the approval of the LP and the LI indicated that in 
$61.16 \%$ of the considered cases it took from 15 to 35 months for the second environmental license to be issued.

Regarding the time needed for a license to be approved based on the SIMLAF data and on the specifications from the Normative Instruction $184 / 2008^{3}$, it can be said that the definition of deadlines by the legislation is not sufficient to ensure the celerity of the process, for the deadlines determined for each procedure do not take into account aspects such as: the time necessary to elaborate an Environmental Impact Study, the cases where the project does not comply entirely with the Term of Reference, the indefinite amount of times the study can be returned to be complemented and other technical and bureaucratic aspects that can interfere in the time it takes for a license to be approved.

Taking for instance the time elapsed between the presentation of the EIA to the environmental agency and the issuance of the Previous License (the following phase after the EIA is analyzed and approved), the Normative Instruction previously mentioned establishes a deadline of 180 days (six months) for the Studies to be analyzed. Nevertheless, the average time frame for the processes analyzed on this study was 19.3 months for this phase and in some cases it lasted up to 30 months. This situation may be explained by several reasons, whether they are responsibility of the environmental agency or of the license requester. These reasons will be analyzed on the item about the quantitative analysis of the licensing process in this article.

\subsubsection{Analyzing the Number of Conditions per License}

In a comparative analysis between the average values of the three types of licenses, it is possible to determine that it is in the process of obtaining the operating license that there is the highest amount of conditions required, which can be seen on Figure 3 .

Nevertheless, as in the analysis of the time elapsed for the license issuance, the quantitative analysis of the conditions determined by the environmental agency for each of the stages (LP, LI and LO) presented a high dispersion value. This characteristic of the sampling makes it difficult to define the reference values that would enable a prediction of the quantity of conditions required on each licensing stage.

When the sampling distribution of each license type was analyzed, it was concluded that, for the 24 LPs analyzed, $70.8 \%$ were issued with a minimum of 10 conditions and a maximum of 60 . As for the LIs, $68.4 \%$ of them are on that same gap. For the 16 LOs analyzed, in $81.2 \%$ of them the amount of conditions was between 30 and 90.

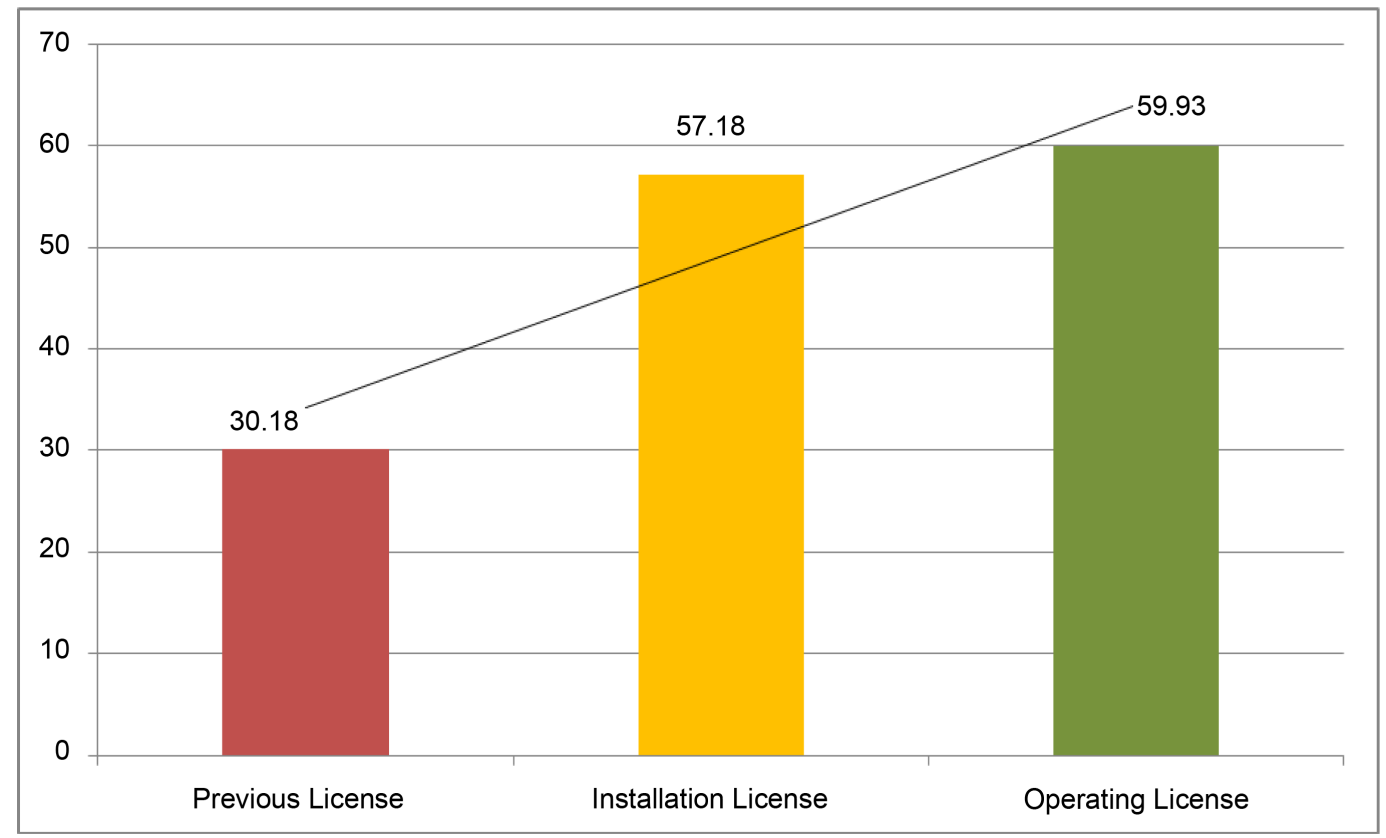

Figure 3. Comparison of the average of conditions for type of license.

${ }^{3}$ Normative Instruction created by IBAMA to determine the details of the procedures and deadlines of the licensing process on the federal level. 
Another analysis was made by adding the number of conditions of each license category for the 16 projects registered in SILAMF and for which there is data from the beginning of the process until the approval of the Operating License.

In this case, the average obtained was 147.3 conditions per project. The standard deviation, however, was extremely high, 95.5. Therefore, this average cannot be considered a reference value.

On the analysis of the sampling distribution, most of the values have been found on a wide range: $70 \%$ of the cases had between 50 and 200 conditions.

Based on the comparative analysis of the total sum of each license's conditions, it is possible to make a few observations. First, the operating license phase of the projects is more demanding regarding the amount of conditions. Second, there is a considerable increase on the amount of conditions between the previous license phase and the two following phases-there is an increase of more than $98 \%$ on the amount of conditions between the first and last licenses, as demonstrated in the following graphic on Figure 4.

The analyzed data corroborate the existence of a high level of uncertainty on the environmental licensing process of hydropower plants, especially for the project manager (the license requester). This uncertainty regarding the time it takes for a license to be issued and the fact that the averages were higher than the deadlines determined by legislation have significant consequences. First, the project manager becomes more uncertain about the planning of the project and consequently about how long it will take before there is a return on capital, which may reduce the interest of the private sector and of public-private partnerships willing to invest on hydroelectric generation. Other generation modalities, such as thermoelectric, may seem more appealing due to the lower level of uncertainty.

In addition, the unpredictability of the time needed for a license to be issued and of the the costs of an environmental authorization process affects the final value of the produced energy because the project manager determines a higher rate of return in order to decrease the costs of regulatory uncertainty inherent to the licensing process.

These circumstances put in jeopardy the government's plan for the electric energy sector, which establishes, on the Decennial Energy Expansion Plan for 2020, that 48 hydropower plants should begin operating with a total power of about 42.000 MW. Of these 48, 30 still lack a Previous License, and therefore they are considered as planned [17]. Adding a final comment, the uncertainty of the environmental licenses deadlines may also be a risk for the supply of electrical energy for industries and households in the country over the next decade. According to the Decennial Plan previously mentioned, the electrical energy used will be $659.092 \mathrm{GWh}$ until 2020, 283.707 GWh on the industrial sector and $166.88 \mathrm{GWh}$ on households.

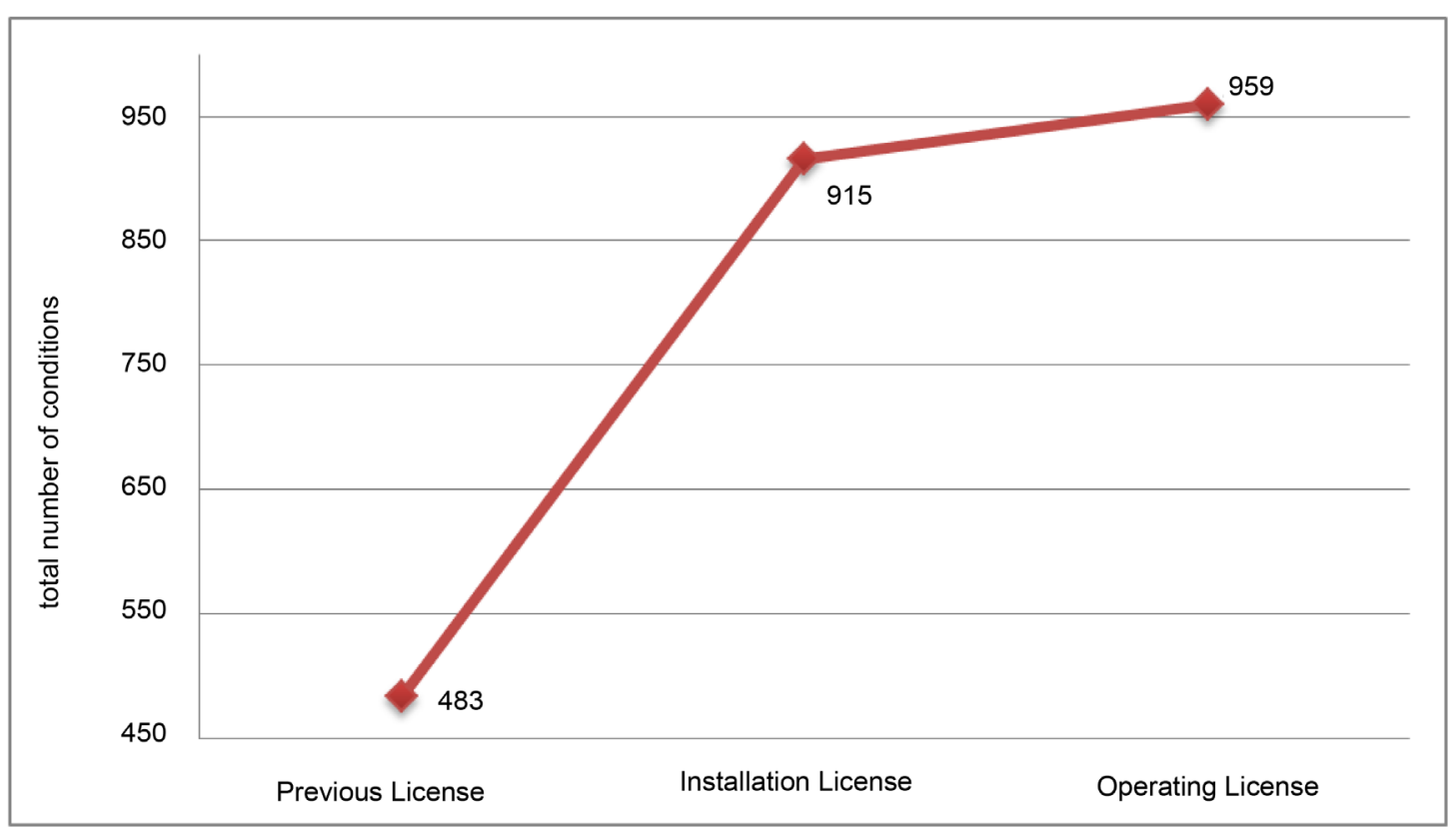

Figure 4. Comparison of the total of conditions for type of license, in all projects analyzed (n 16). 


\subsection{Qualitative Analysis of the Environmental Licensing Process of Hydropower Plants}

Firstly, it is necessary to take into consideration the challenges inherent to the environmental licensing process of hydropower projects-they are considerable even if institutional organization and normative regulations are ideal. The studies needed to analyze the impacts and the best alternatives are complex and of great importance.

Nevertheless, the difficulties inherent to the environmental licensing of hydropower plants increase due to the existence of institutional and legal deficiencies, or even due to political and economical issues that may arise during the process. In addition, the failure of past hydroelectric projects has created a negative perception of the environmental licensing process in the country. In some cases, it even affects the decision of constructing new hydropower plants.

According to the study made by the Center of Studies and Research of the Federal Senate: there are two different perspectives on environmental licensing in Brazil-"For some segments of society, it is an obstacle, a way to decrease the interest in making large investments on infrastructure, therefore hindering the creation of jobs and more income. To other segments, it is a corrupted process through which capitalism imposes its will, buying consciences and degradating the environment. Between these two extremes, there is only an increase on the level of disinformation and, even worse, a lack of interest in improving this mechanism.” [18].

Considering the perspectives of [18]-[21] regarding the problems of environmental licensing in Brazil, the challenges and obstacles of the process can the summarized in five different lines of approach:

1) Difficulty in coordinating the different spheres of government involved in the process

In spite of the legal instruments that try to discipline the relationship between the Union, the States and the Municipalities on the subject of environmental licensing and other issues related to the environment, there are still cases in which there is a clear lack of limits for where each different governmental sphere should act. The functions of the different agencies overlap with each other, which contributes to the delay between the licensing phases.

2) Insufficient technical skills

In the last three years, the projects focused on exploration of renewable energies (which include hydroelectric dams, small hydroelectric centrals and aeolic energy) required a significant quantity of environmental licenses, whether they were new or a renewal of old licenses. Only the infrastructure projects (more specifically roadways, ports and transmission lines) were more abundant.

Between January 2010 and September 2012, 1.083 new licenses and authorizations were issued by IBAMA. Of this total, $22 \%$ were licenses related to hydropower plants, adding up to 241 new licenses and authorizations. In addition to the new licenses, there is also the renewal and rectification of licenses that already existed. On that same time period, 246 licenses were renewed or extended and 234 were rectified.

Among the productive, industrial and economic sectors, this was the largest increase on the number of licensing processes in Brazil over the last three years. Not even transport infrastructure, the main requester of federal environmental licensing, had such an increase.

Given that, certain aspects should be considered. First, this clearly indicates that one of Brazil's main development goals is to increase its energy supply. Second, IBAMA's ability to ensure the rapidity of the licensing processes should be questioned without affecting the quality and impartiality of the issuing and renewal of the licenses.

In this sense, it is worth remembering that the issuing of new licenses and authorizations, similarly to their renewal or rectification, requires technical analysis and bureaucratic procedures that depend on the work of the employees of the environmental agency, especially in the case of licensing for hydropower plants, for their analyses are extremely complex and time demanding. According to the auditing report of the Office of The Comptroller General about IBAMA's work on 2010, the amount of employees of the agency was considered insufficient for it to perform its institutional tasks [20].

According to the study made by the Office of the Comptroller General, the situation worsens due to the fact that 70 workers retired in 2010 and about $17 \%$ of the current workers have already fulfilled the minimum requirements to apply for voluntary retirement. This percentage will increase considerably over the next years for over $40 \%$ of the workers are at least 50 years old.

In spite of the fact that a college degree is necessary to become an Environmental Analyst for IBAMA and that a high percentage of employees have graduate degrees, the study made by the Court of Accounts of the Union in 2008 showed that there is a lack of employees with skills in some specific areas of knowledge that are 
necessary for the analysis of a Environmental Impact Study [20]. Similarly, the World Bank Report affirms that there is a lack of workers with a background on social sciences on the environmental agencies [15].

A larger amount of employees with a social sciences or humanities background would aid the decision making process of solving conflicts that are inherent to the environmental licensing. In addition, it would help define more clearly which are the rules for social compensation, especially when dams are being constructed, for their impacts tend to affect the local communities very directly. There are cases in which the entire population of the area needs to be removed so that the reservoir can be filled. Situations are even more complex when construction affects native Brazilian communities and villages or requires their removal.

3) Technical Quality of the Environmental Impact Studies: Questionable

The questionable quality of some EIAs can be attributed to several factors. For instance, the project manager may wish to obtain the license in a faster and cheaper way, making the study in little time and with a small group in order to lower the costs. Also, the database for basic environmental research is very limited, which can be easily observed by the lack of an efficient information system capable of storing and sharing the data from environmental studies, report analysis and technical notes [20].

The low quality of the Impact Studies affects the analyses of potential impacts, which in its turn affect the decisions that are made regarding possible alternatives to the project and the definition of the best mitigation and compensation measures. In addition, the licensing process becomes longer. Where the EIA does not meet all the requirements from the Term of Reference approved by the environmental agency, or in case its quality is not good enough, it must be complemented, corrected and presented again as many times as requested by the agency.

4) Conflicts and Society Participation

Nowadays, it is through a Public Hearing that society can participate on the decision process. However, the current model and the results obtained through them are questionable. The criticisms to the public hearing model in Brazil state that society participation is usually overestimated, distorted and at times it comes too late. One of the factors that distort the hearing process is the representativity, which is questionable quantitatively and qualitatively. According to an analysis of the Center of Research and Studies of the Senate, "the tendency is that the groups who have a lot to win or lose with one specific project are the ones who participate more intensely than the rest of society and, in these cases, the pressure they create can form a favorable or unfavorable opinion to the project. That is something evident on the environmental sector, where groups fearing negative external consequences of the project mobilize themselves while the sectors that would be benefited-the rest of society-do not have any opinion” [18].

It is not rare for public hearings to be scheduled because there is a conflict between groups with different interests. The discussions become ideological conflicts with subjective arguments and information who does not have any scientific or technical foundation.

5) Regulatory uncertainties and costs associated to the process

The regulatory uncertainty is one of the factors that increase the financial return, affecting the final price of the MWh [15]. The most important aspects that increase this uncertainty are:

- The politicization of managing positions of the public sector, which reflect on the quality of the administration, as well as the political conflicts that happen inside the environmental sector agencies;

- A larger influence of subjective and ideological arguments;

- The legal disputes within the decision process, which are common and motivated especially by Public Ministry actions;

- The political pressure for a speedy assessment and approval of projects considered high priority [18]. It is worth mentioning that $68 \%$ of the projects analyzed on this article are included on the goals of the Growth Acceleration Program (PAC), a program focused on infrastructure and on primary sectoral investments which have specific deadlines that cannot be extended.

\section{Conclusions}

This article aimed to point out which are the main challenges and flaws on the environmental licensing process in Brazil, so as to bring contributions and proposals to make the current model more efficient. Efficiency, in this case, would be evaluated through the following aspects: a higher capacity to mitigate and compensate socio-environmental impacts; a higher effectiveness as an instrument for decision making; greater speediness with a 
smaller bureaucracy; a less intrusive presence of the agencies and social sectors involved, with less political and ideological interferences.

To reach these goals, a few measures and changes can be suggested:

- The use of planning instruments already existing (Public Policies, Governmental Plans and Programs, Integrated Environmental Assessment-AAI, Strategic Environmental Assessment-AAE) for guiding the construction of the Term of Reference of the EIA and predicting which issues and challenges may arise on the licensing phase. In other words, the environmental licensing process should be integrated with the planning process of different areas. In the case of hydropower plants, planning should be integrated with the territorial zoning and the planning of infrastructure, mining, energy and water resources. These plans should share the same goals and, more importantly, they should serve as a base for environmental impact studies. Each national hydrographic basin should not only have a Management Plan, but also a viability study before the water resources and the land are used. This study should point out fragilities and potential impacts related to each kind of water resource use, enabling a faster and more reliable elaboration of the TRs and the EIAs.

- The Previous License should be issued based on the analysis made during the planning stage involving several instruments (Policies, Plans and Programs, AAI, AAE) and interested agencies. Thus, the EIA of the project would be a requirement for the issuance of the LI and it would be based on the engineering project and its local impacts.

- The creation of a more efficient information system that stores and shares environmental studies, analyses, reports and technical notes. This system should provide an environmental database to be a reference for impact studies and environmental programs which are conditions of the licensing process.

- More IBAMA employees with technical skills, with better incomes and career plans, improving the selection process and avoiding the current evasion of technical employees in search of jobs with better salaries and opportunities.

- The creation of other mechanisms through which society can participate and express opinions, complementing the Public Hearings. These could be on-going and used in different phases of the process.

\section{Acknowledgements}

The author would like to thank the National Council of Technological and Scientific Development of the Federal Government of Brazil for funding his PhD studies; IVIG-International Virtual Global Change Institute for their technical and financial support in organizing meetings with government bodies, researchers and members of the civil society, as well as funding technical visits and trips related to his research and to this article; and the Computational Hydraulics Laboratory of the Civil Engineering Department of the Federal University of Rio de Janeiro for its technical and academic support and for giving him the opportunity to work on his PhD thesis and on this article in particular.

\section{References}

[1] Eletrobras (2015) Sistema Brasileiro de Informações do Potencial Hidrelétrico (SIPOT).

[2] Bechberger, M. and Reiche, D. (2004) Renewable Energy Policy in Germany: Pioneering and Exemplary Regulations. Energy for Sustainable Development, 8, 47-57.

[3] Georgopoulou, E., Sarafidis, Y. and Diakoulaki, D. (1998) Design and Implementation of a Group DSS for Sustaining Renewable Energies Exploitation. European Journal of Operational Research, 109, 483-500. http://dx.doi.org/10.1016/S0377-2217(98)00072-1

[4] Resch, G., Held, A., Faber, T., Panzer, C., Toro, F. and Haas, R. (2008) Potentials and Prospects for Renewable Energies at Global Scale. Energy Policy, 36, 4048-4056. http://dx.doi.org/10.1016/j.enpol.2008.06.029

[5] Pereira, M.G., Freitas, M.A.V. and da Silva, N.F. (2011) The Challenge of Energy Poverty: Brazilian Case Study. Energy Policy, 39, 167-175. http://dx.doi.org/10.1016/j.enpol.2010.09.025

[6] Brasil (2007) Ministério de Minas e Energia. Plano Nacional de Energia 2030/Ministério de Minas e Energia; colaboração Empresa de Pesquisa Energética. Brasília, 324 p.

[7] World Commission on Dams (2000) Dams and Development: A New Framework for Decision-Making. The Report of the World Commission on Dams, Earthscan Publications Ltd., London and Sterling.

[8] Heinma, K. and Põder, T. (2010) Effectiveness of Environmental Impact Assessment System in Estonia. Environmental Impact Assessment Review, 30, 272-277. http://dx.doi.org/10.1016/j.eiar.2009.10.001 
[9] Che, X.Z., English, A., Lu, J. and Chen, Y.Q.D. (2011) Improving the Effectiveness of Planning EIA (PEIA) in China: Integrating Planning and Assessment during the Preparation of Shenzhen's Master Urban Plan. Environmental Impact Assessment Review, 31, 561-571. http://dx.doi.org/10.1016/j.eiar.2010.12.003

[10] Nykvist, B. and Nilsson, M. (2009) Are Impact Assessment Procedures Actually Promoting Sustainable Development? Institutional Perspectives on Barriers and Opportunities Found in the Swedish Committee System. Environmental Impact Assessment Review, 29, 15-24. http://dx.doi.org/10.1016/j.eiar.2008.04.002

[11] Pölönen, I., Hokkanen, P. and Jalava, K. (2011) The Effectiveness of the Finnish EIA System-What Works, What Doesn't, and What Could Be Improved? Environmental Impact Assessment Review, 31, 120-128. http://dx.doi.org/10.1016/j.eiar.2010.06.003

[12] Samarakoon, M. and Rowan, J.S. (2008) A Critical Review of Environmental Impact Statements in Sri Lanka with Particular Reference to Ecological Impact Assessment. Environmental Management, 41, 441-460.

[13] Villarroya, A. and Puig, J. (2011) Ecological Compensation and Environmental Impact Assessment in Spain. Environmental Impact Assessment Review, 30, 357-362.

[14] Paliwal, R. (2006) EIA Practice in India and Its Evaluation Using SWOT Analysis. Environmental Impact Assessment Review, 26, 492-510. http://dx.doi.org/10.1016/j.eiar.2006.01.004

[15] World Bank (2008) Licenciamento Ambiental de Empreendimentos Hidrelétricos no Brasil: Uma contribuição para o debate (3 volumes) Volume I: Relatório Síntese. World Bank Country Office in Brazil. Economic and Sectoral Study. Latin America and Caribbean.

[16] International Energy Agency (2012) Key World Energy Statistics. Paris, 82 p.

[17] Brasil (2011) Ministério de Minas e Energia, Empresa de Pesquisa Energética. Plano Decenal de Expansão de Energia 2020. Brasília, DF.

[18] Faria, I.D. (2011) Ambiente e Energia: Crença e Ciência no Licenciamento Ambiental; Parte III: Sobre alguns dos problemas que dificultam o licenciamento ambiental no Brasil. Núcleo de estudos e pesquisas do senado. Brasília, 33 p.

[19] Lima, L.H. and Magrini, A. (2010) The Brazilian Audit Tribunal's Role in Improving the Federal Environmental Licensing Process. Environmental Impact Assessment Review, 30, 108-115. http://dx.doi.org/10.1016/j.eiar.2009.08.005

[20] TCU, Tribunal de Contas da União (2008) Relatório de Auditoria de Natureza Operacional sobre o licenciamento ambiental Federal (TC 022.564/2007-9).

[21] Brasil (2011) Controladoria Geral Da União. Relatório Anual de Auditoria Anual de Contas, IBAMA Exercício 2011. Brasília, DF, 122 p. 